\title{
Influencia morfoestructural en la génesis de los procesos de arenización en Rio Grande do Sul, Brasil ${ }^{1}$
}

\author{
Dirce Maria Antunes Suertegaray², Laurindo Antônio Guasselli², \\ Clódis de Oliveira Andrades Filho ${ }^{2}$
}

\begin{abstract}
RESUMEN
La arenización es un proceso de degradación del suelo derivado de la acción hídrica y eólica, que acarrea una dificultad de fijación de la cobertura vegetal en áreas con un substrato fragilizado. Por este motivo la región sudoeste del Rio Grande do Sul es identificada como área de especial atención por el Ministerio de Medio Ambiente. Esta región se ubica en la Cuenca del Paraná con embasamiento constituido por gran cantidad de zonas de flaqueza, separando este embasamiento en bloques de fallas. A través de la investigación de la génesis de esos procesos se constató la relación entre alienaciones estructurales y la disposición del drenaje, la orientación de relieve y la ocurrencia de arenales, siendo uno de los procesos fundamentales de investigación el tratamiento de la imagen SRTM.
\end{abstract}

Palabras clave: Arenización, arenales, lineamientos estructurales.

\begin{abstract}
Sandization is a degradation process of the soil controlled by hidric and eolic action, which makes difficult the fixation of vegetal cover in areas with weak substratum. Given this reason, the southeast region of Rio Grande do Sul is identified as a special attention area by Ministry of Environment. The region is located at Paraná Basin and its basement is formed by many weak zones, divided in fault blocks. Through investigation of this processes genesis, it was possible to relate structural lineaments, drainage disposition, relief orientation and sand field occurrences. One of the most fundamental processes in this research is the treatment of SRTM images.
\end{abstract}

Key words: Sandization, sand fields, structural lineaments.

En un principio, se hace necesario conceptualizar el significado e implicancias de los términos desertificación y arenización. En la Conferencia de Nairobi (1977) desertificación fue definida como la disminución o la destrucción del potencial biológico de la Tie-

1 Artículo recibido el 17 de septiembre de 2007 y aceptado el 16 de febrero de 2008. rra, que pudiere desencadenar en condiciones del tipo desierto. En Brasil, solamente en el Nordeste del país se reconoce este proceso. Rio Grande do Sul no se presenta como una región afectada por la desertificación. Las razones son claras: Rio Grande do Sul

\footnotetext{
2 Universidade Federal do Rio Grande do Sul UFRGS Dept. Geografia/CEPSRM (Brasil).

E-mail: suerte.ez@terra.com.br,

laurindo.guasselli@ufrgs.br, clodisfilho@terra.com.br
} 
tiene su ubicación geográfica en una región de clima subtropical, con precipitación media anual de $1.400 \mathrm{~mm}$. En consecuencia, se encuentra fuera de la zona donde el clima, juntamente con la acción del hombre, han sido motivo principal de degradación.

Por arenización se entiende el proceso de retrabajo de depósitos arenosos poco consolidados o inconsolidados, que desencadena una dificultad para la fijación da la cobertura vegetal, debido a intensa movilidad de sedimentos por la acción de las aguas y de los vientos. La región sudoeste del Estado de Rio Grande do Sul, en particular el municipio de Alegrete, es identificada como área de atención especial (Ministério de Meio Ambiente, 1997). Esta región presenta un fuerte control estructural asociado a la evolución tectónico-sedimentar de esta región. Existe una marcada influencia de las direcciones estructurales inherentes al basamento, constituido por una gran cantidad de zonas de debilidad que se cruzan, conformando un basamento fracturado en bloques de fallas.

Esta investigación se orientó a la evaluación de la influencia de la estructura en la génesis de los arenales. Las herramientas fundamentales para el cumplimiento de los propósitos establecidos corresponden a la imagen SRTM (Shuttle Radar Topography Mission), y los siguientes procedimientos realizados:

a) Aplicación del uso de la imagen SRTM para la identificación de rasgos estructurales, espacialización de datos de orientación del relieve y delimitación de drenaje en detalle;

b) Análisis de la relación entre las alienaciones estructurales con la disposición del drenaje, orientación de los taludes y la ocurrencia de arenales.

\section{Materiales y métodos}

\section{Área de estudio}

La región de ocurrencia del proceso de arenización está localizada en el sudoeste de Rio Grande do Sul (Figura № 1 ), a partir del meridiano de $54^{\circ}$ en dirección Oeste, hasta la frontera con la Argentina y la República Oriental del Uruguay. Esta región se

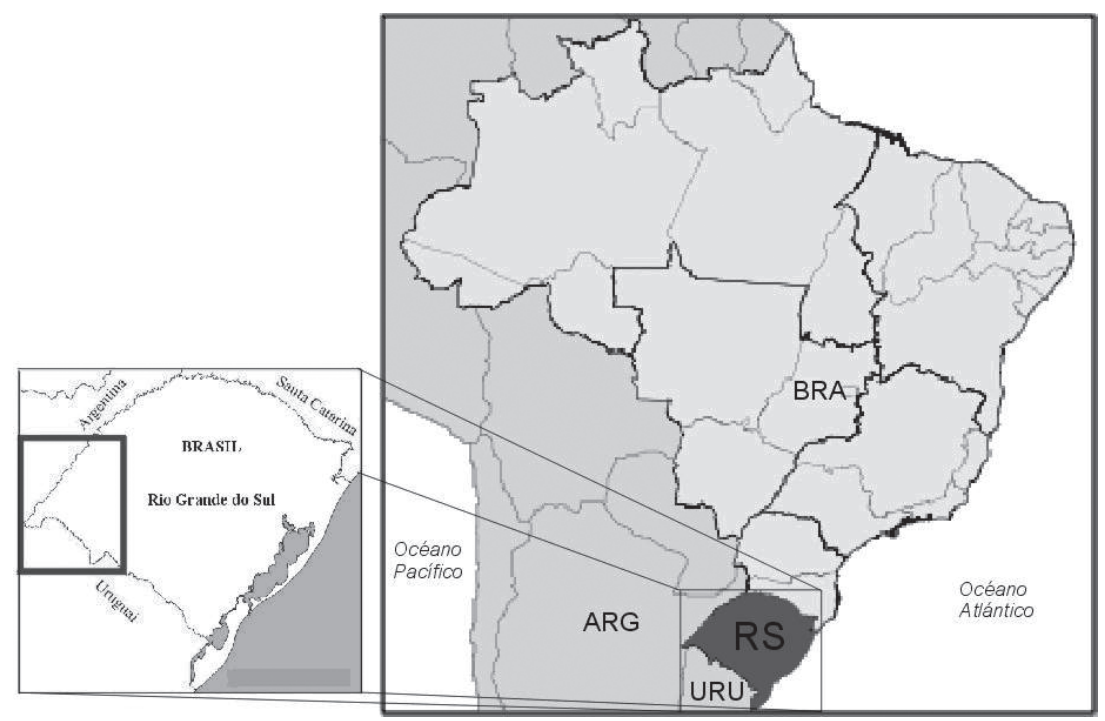

Fuente: Elaboración propia. 
ubica en la cuenca del río Paraná, una cuenca intercratón desarrollada por completo sobre una corteza continental, que fue rellenada con rocas sedimentarias y volcánicas, cuyas edades varían desde el Ordovícico hasta el Cretácico. La evolución tectónicosedimentaria de esta cuenca ha estado bastante controlada por las direcciones de los lineamientos estructurales inherentes al basamento, constituido por una gran cantidad de zonas de debilidad estructural, entrecruzados, separando el basamento en bloques de fallas. Las zonas de debilidad estructural actúan como los principales agentes de disipación de tensiones interplaca que permiten movimientos recurrentes de esos bloques a lo largo de esas zonas (Zalán, 1991 citado en Frasca, 1996).

\section{Proceso de formación de arenales}

El área de ocurrencia de los arenales tiene como substrato las areniscas de la Formación Botucatu; en esta formación Mesozoica se asientan depósitos arenosos no consolidados, originarios de depositación fluvial y eólica durante el Pleistoceno y el Holoceno.
Procesos de remoción actual generan tales arenales (Figura $\mathrm{N}^{\circ} 2$ ).

Los arenales están presentes en el sector medio de los taludes de las colinas o en contacto con escarpas de cerros testigos (Figura $\mathrm{N}^{\circ} 3$ ). El análisis de la formación de los arenales, interpretada por estudios geomorfológicos, asociada a la dinámica hídrica y eólica, indica que el origen de estos arenales es la resultante de procesos hídricos, que, interrelacionados con una topografía favorable, permiten, en una primera fase, la formación de surcos y cárcavas. Los procesos continúan a través del desarrollo de erosión lateral y regresiva, ampliando consiguientemente los bordes. Además, hacia la zona distal de los surcos y cárcavas, y ligado a los procesos de transporte de sedimentos por el agua durante episodios de lluvias torrenciales, se forman depósitos arenosos en forma de abanico. Con el tiempo, estos microconos aluviales coalescen y, en conjunto, originan un arenal. La deflación eólica sobre estos depósitos contribuye a la amplitud del proceso.

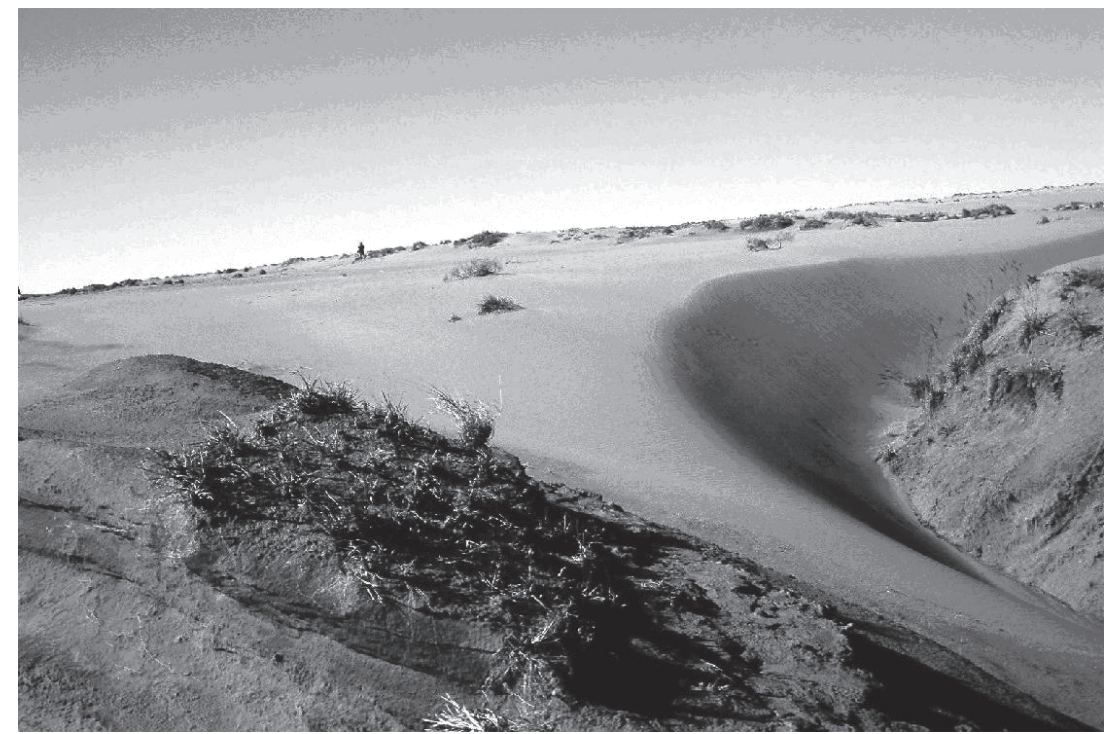

Fuente: Trabajo de campo. 
Figura $\mathrm{N}^{\circ} 3$

OCURRENCIA DE ARENALES EN EL SECTOR MEDIO DE LOS TALUDES DE LAS COLINAS
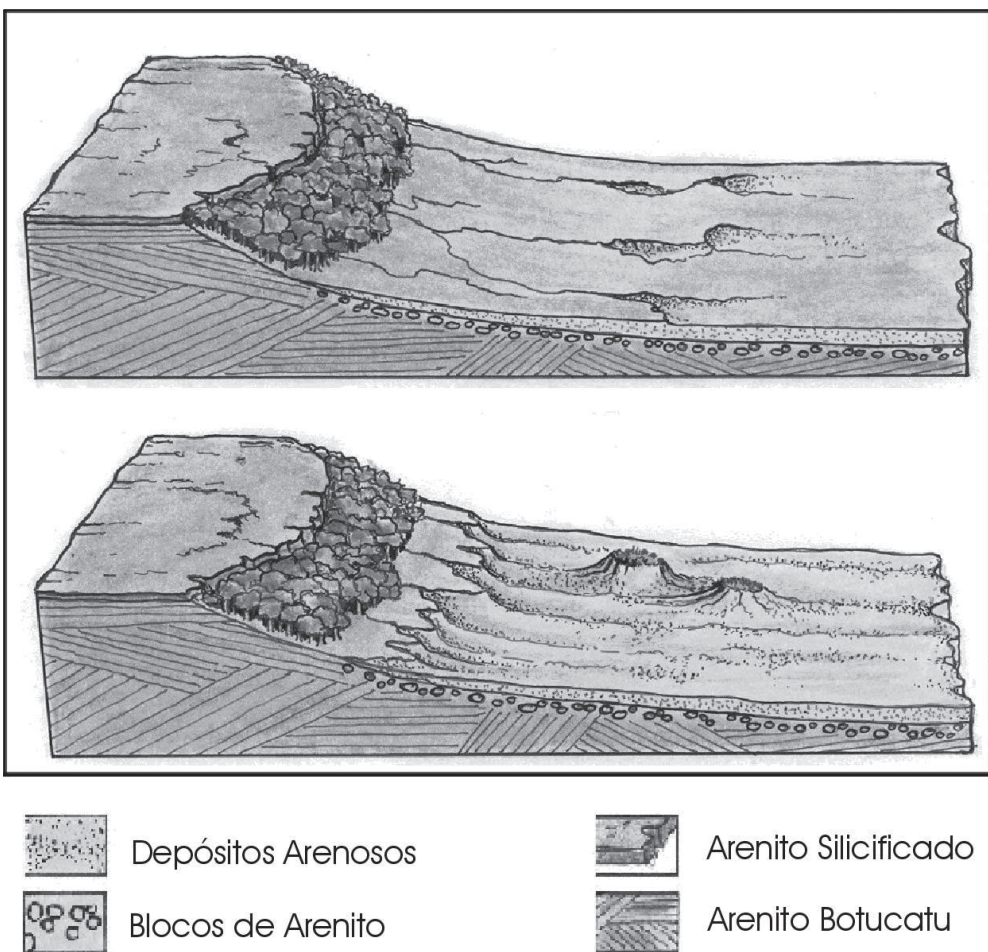

Fuente: Suertegaray et al (2001).

Figura $\mathrm{N}^{\circ} 4$

OCURRENCIA DE ARENALES EN SECTORES MEDIOS DE LAS VERTIENTES

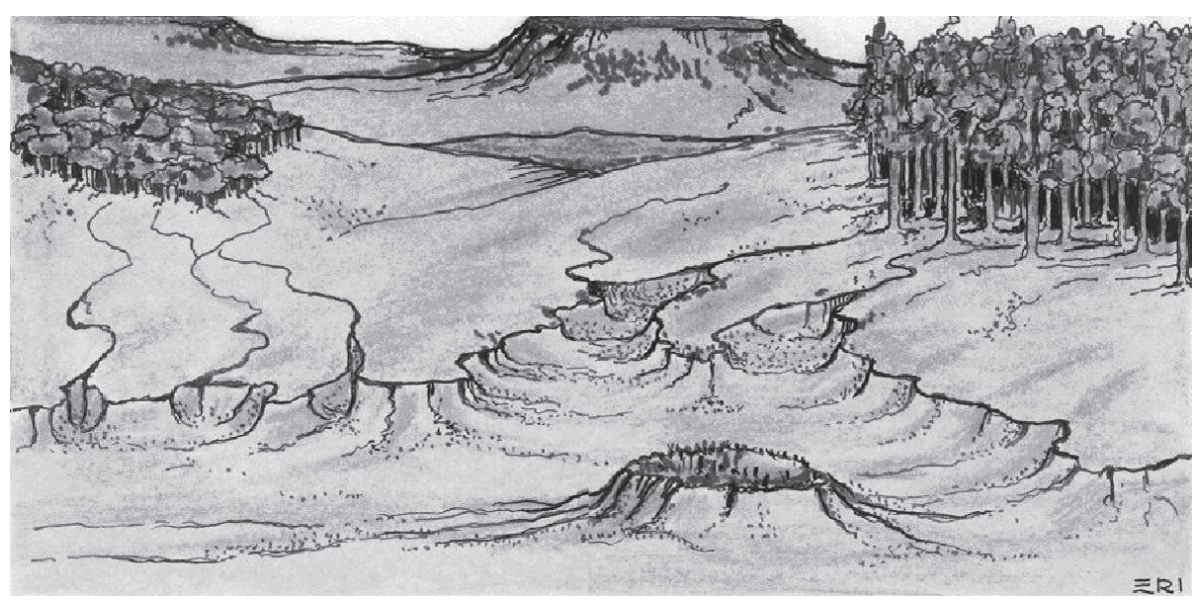

Fuente: Suertegaray et al. (2001). 


\section{Área de la investigación}

El presente trabajo se circunscribe a cinco cuencas hidrográficas de la región al norte del rio Ibicuí, con gran ocurrencia de procesos de arenización: cuenca del Arroyo Piraju, cuenca del Arroyo Inhacundá, cuenca Sanga del Araçá, cuenca del Miracatu y cuenca del Caraguataí (Figura No 5).

\section{Procedimientos}

La primera etapa del trabajo consistió en la especialización de los arenales, realizada a través del uso de la imagen Landsat TM 5 con fecha 1989, por clasificación digital nosupervisada (Andrades Filho et al., 2006).

En el análisis previo realizado sobre el comportamiento espectral de los arenales, a partir de los contadores digitales de la imagen banda 5 del Landsat TM (Figura $N^{\circ}$ 6), se adoptó un intervalo de valores del tono de ceniza de 190 a 255 para delinear. La banda 5 fue usada porque ofrece una mayor diferenciación en cuanto al tipo de suelo y las condiciones de humedad del mismo.

Figura $N^{\circ} 5$

CUENCAS HIDROGRÁFICAS ESTUDIADAS Y ESPACIOS DE LOS ARENALES

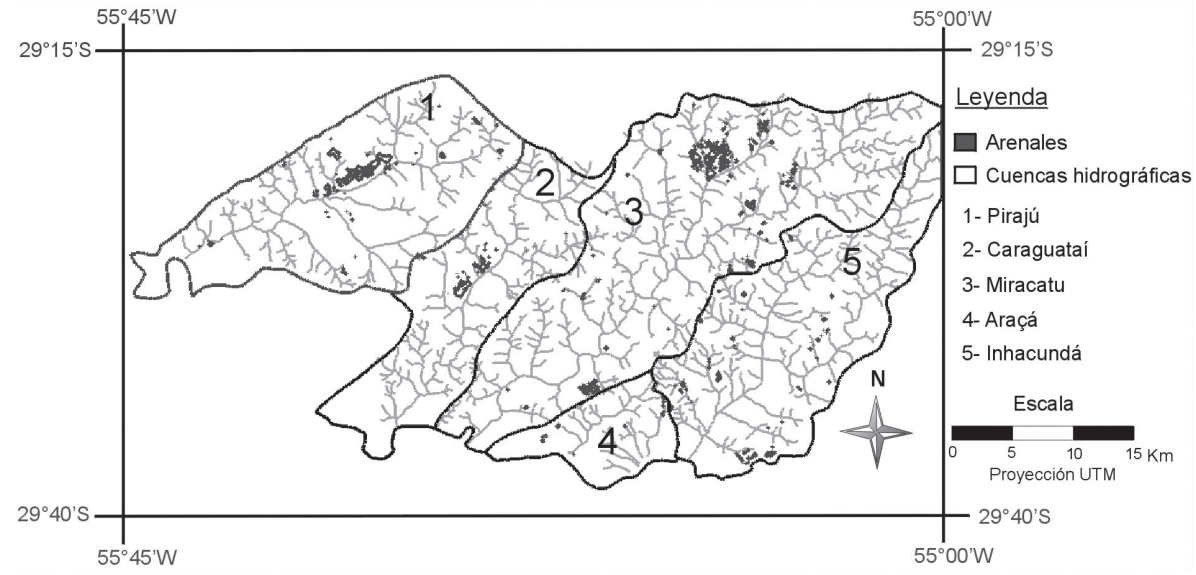

Fuente: Adaptación de Andrades Filho et al. (2007).

Figura $\mathrm{N}^{\circ} 6$

IMAGEN LANDSAT TM NA BANDA 5 CON IDENTIFICACIÓN DE AREAS DE ARENALES

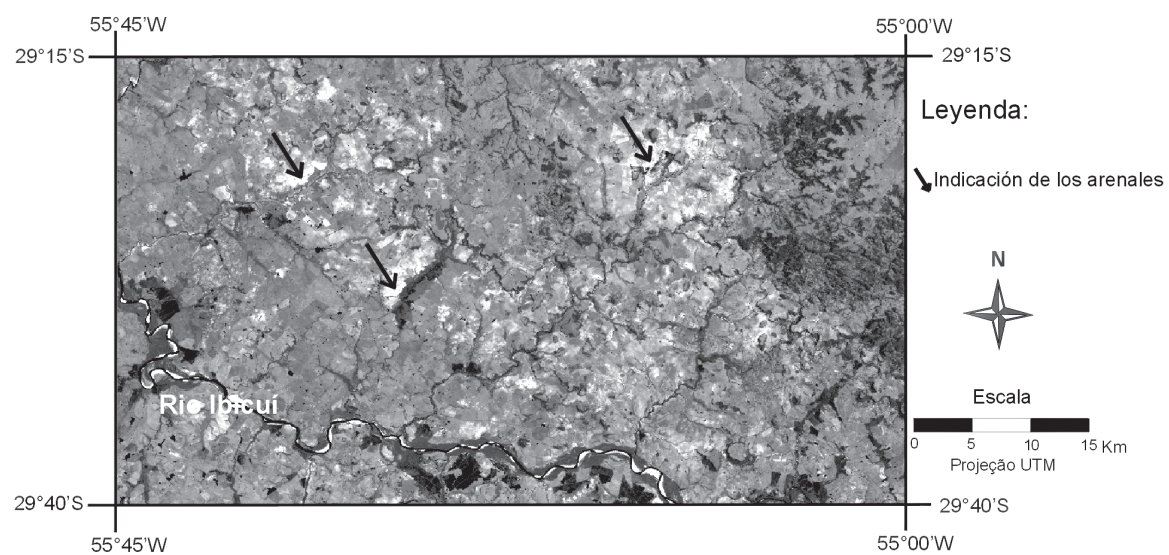

Fuente: Elaboración propia. 
Este método fue elaborado con el uso del lenguaje de programación LEGAL (Lenguaje Espacial para Geoprocesamiento Algebraico) del Spring, en las imágenes de 1989. Después del delineado de las imágenes se realizó un análisis visual, mediante el cual fueron eliminadas las áreas con comportamiento espectral semejante, pero no consideradas áreas de arenización, según su génesis, como por ejemplo, las áreas de los bancos arenosos a largo de los cursos de agua (Figura 7-A) y las áreas de suelo expuesto debido a labores de preparación para la agricultura (Figura 7-B).
En estas primeras etapas fue fundamental el uso del SIG SPRING. Este posee funciones de procesamiento de imágenes, análisis espacial, modelado numérico del terreno y consulta a bancos de datos espaciales. Corresponde a un proyecto brasileño elaborado por el INPE (Instituto Nacional de Pesquisas Espaciais).

\section{Procesamientos de imágenes SRTM}

Para la generación de la base digital del drenaje de las cuencas hidrográficas estudiadas, de los mapas de aspecto y linea-

Figura $\mathrm{N}^{0} 7$

ÁREAS ELIMINADAS CON COMPORTAMIENTO ESPECTRAL SIMILAR A LOS ARENALES. BANDA 5, LANDSAT TM 5
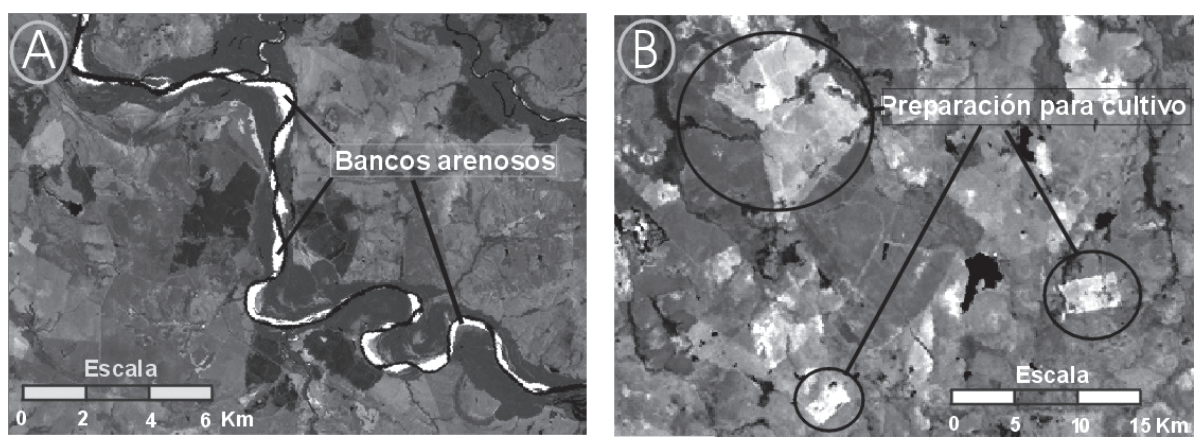

Fuente: Elaboración propia.

Figura $\mathrm{N}^{\circ} 8$

IMAGEN SRTM/NASA

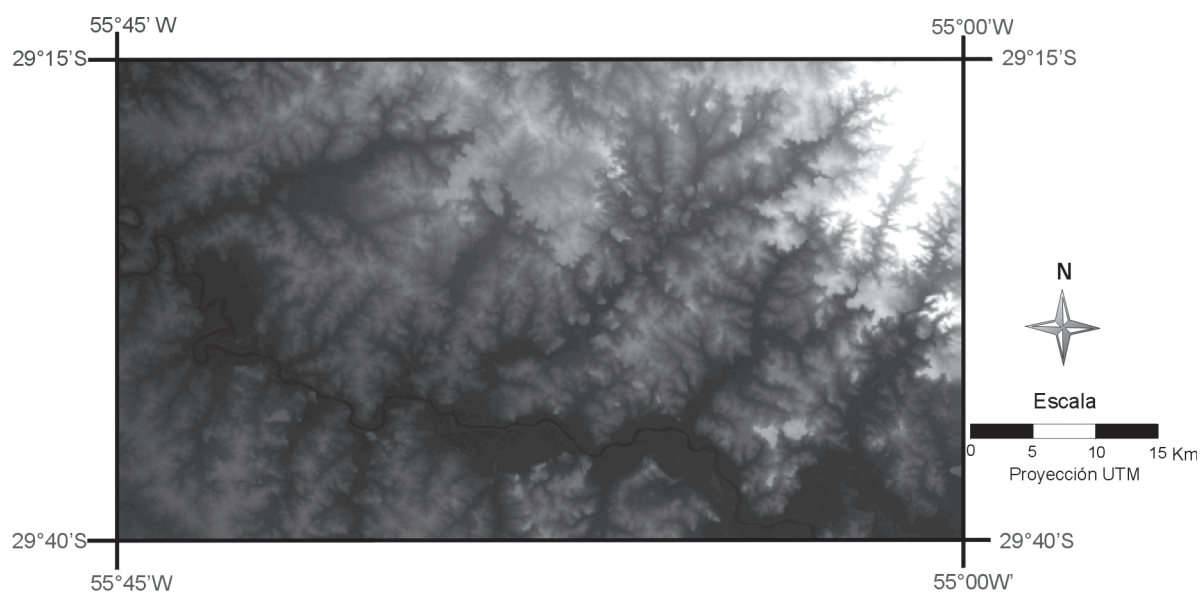

Fuente: National Aeronautics and Space Administration -NASA (2003). 
mientos, fue utilizada la imagen SRTM (Shuttle Radar Topography Mission), entre las coordenadas $29^{\circ} 15^{\prime} \mathrm{S}$ y $29^{\circ} 40^{\prime} \mathrm{S}$ y $55^{\circ} 45^{\prime} \mathrm{W}$ y $55^{\circ} 00^{\prime} \mathrm{W}$ (Figura $\mathrm{N}^{\circ} 8$ ), con resolución espacial de 90 m conseguida a través de Ftp de la NASA. Los datos de la Shuttle Radar Topography Mission (Farr et al., 2007) son el resultado de una misión espacial de la NASA (National Aeronautics and Space Administration), NIMA (National Imagery and Mapping Agency), DLR (Agencia Espacial Alemana) y la ASI (Agencia Espacial Italiana), realizada en el año 2000, con el objetivo de generar un Modelo Digital de Elevación (DEM) de la Tierra usando la interferometría.

La descarga de la imagen SRTM fue realizada en formato $\mathrm{HGT}$, con el uso del programa ENVI 4.2 para la transformación a formato I GeoTiff, compatible con el Spring 4.3.

A partir de la imagen SRTM en la resolución de $90 \mathrm{~m}$ fue ejecutado un método de interpolación sobre la imagen (Valeriano, 2004) para obtener una resolución de $20 \mathrm{~m}$. Este procesamiento constituyó la modificación del Modelo Digital de Elevación - MDE SRTM original en un nuevo MDE, con las características deseables. Entre las modificaciones pretendidas, se cuenta con: la remoción de las fallas y la resolución mejorada (20 metros). Los programas computacionales utilizados en el tratamiento fueron: ENVI 4.2: corrección de fallas, selección de área de muestreo y exportación de datos ASCII; SURFER 3.2: interpolación; SPRING 4.3 del INPE, para tratamiento de imagen, digitalización del drenaje, levantamiento cartográfico, mapa de orientación de las vertientes y lineamientos estructurales.

Con el software ENVI fueron realizadas las siguientes etapas:

- Corrección de fallas: cargada la imagen (file/open image), fue accionada la corrección vía menú Topography/BadValues, donde se estableció como el intervalo de valores inválidos desde -9999999999... hasta 0, y la imagen corregida fue guardada en la memoria;

- Exportación de archivos ASCII: se accionó la opción del menú File/save file as/
ASCII, definiendo el formato en columnas $x, y, y z$ (botón output style, opción $X Y Z$ format). Se aumentó el formato numérico de las coordenadas ( $X Y$ field size) de 10 a 20 caracteres, de modo que el largo de la página no tuviese más que las 3 columnas deseables.

En el software SURFER se realizó:

- Interpolación: los archivos ASCII de la totalidad de las cotas fueron interpolados por krigage, de modo que la resolución espacial resultante fuese de $20 \mathrm{~m}$.

En el software Spring 4.3 fueron realizadas las siguientes etapas:

- Mapa de orientación del talud: Este mapa de exposición fue producido a partir de una rutina de manipulación de MNT en la herramienta de pendiente, pero con el uso de la imagen SRTM bruta (con resolución de $90 \mathrm{~m}$ ) pues el objetivo del levantamiento cartográfico de estas orientaciones es la observación general de las ocurrencias. Los datos de entrada estaban en el formato de grilla de altimetría y como salida fue generado un mapa de exposición con cuatro clases: NE: $0^{\circ}-90^{\circ}, \mathrm{SE}: 90^{\circ}-180^{\circ}$, SW: $180^{\circ}-270^{\circ}, \mathrm{NW}: 270^{\circ}-360^{\circ}$. Inmediatamente fue realizada una edición matricial con limpieza de píxel (donde el número de píxel (s) es ocho), con el objetivo de obtener la especialización generalizada del talud. Para la comprensión del mapa de orientación en relación a la insolación fueron usados los colores blanco (NE) y ceniza claro (NO), para indicar los taludes con mayor grado de insolación por la mañana y por la tarde, y ceniza oscuro (SO) y negro (SE) para los taludes con menor grado de insolación en este mismo período.

- Cruce de datos: con el uso de los mapas de los arenales (1989) y de orientación de los taludes en formato matricial, fue realizado un cruce y la cuantificación de datos. Para ello se utilizó la Tabulación Cruzada de Spring 4.3.

- Delimitación de los drenajes: para la digitalización del drenaje fueron genera- 
das imágenes de MNT sombreadas. A partir de experimentos, se llegó a tres productos con mayor contraste para la definición y delimitación de los cursos de agua. Estas imágenes poseen diferentes parámetros de iluminación: azimut, elevación y exageración. El primero, define la posición de la fuente luminosa, el segundo, el ángulo de esta fuente con relación a la superficie y el tercero, define el aumento de la escala vertical del terreno.

La digitalización visual del drenaje fue realizada sobre los tres productos resultantes con los siguientes parámetros: Imagen 1 - Azimut: $270^{\circ}$ y elevación: 90 ${ }^{\circ}$, Imagen 2 Azimut: $270^{\circ}$ y elevación: $45^{\circ}$, Imagen 3 Azimut: $10^{\circ}$ e $70^{\circ}$. Todas con valor 70 para la exageración vertical.

- Definición de los lineamientos estructurales: identificación visual a partir de imagen de MNT (producto SRTM) sombreada con los siguientes parámetros: Azimut: $270^{\circ}$, elevación: $45^{\circ}$ y exageración: 70. Este producto presentó una significativa expresión de variaciones del relieve, que permitió el levantamiento cartográfico de los lineamientos según formas, tales como: a) alineaciones representando discontinuidades, con nítida presencia de fracturas estruc- turales; b) alineamientos de escarpas pronunciadas $\mathrm{y} / \mathrm{o}$ estructuras del relieve; c) segmentos rectilíneos de drenaje superficial. Después de esta discriminación fueron definidos como lineamientos principales los que presentaron gran extensión (> $30 \mathrm{Km}$ ), y como alineamientos secundarios los de extensión menor a $30 \mathrm{~km}$ ).

\section{Resultados}

\section{Evidencias en la relación de los arenales con la orientación de los taludes}

El mapa de orientación del relieve en las cinco cuencas hidrográficas (Figura $N^{\circ}$ 9) es un importante producto que posibilitó el cruce el nivel de información correspondiente a la espacialización de los arenales, presentado en el Cuadro $\mathrm{N}^{0} 1$.

En la zona al norte del Rio Ibicuí, la dirección del desagüe del drenaje presenta una orientación sur, donde se encuentra el canal de este río. Esta orientación coincide con la mayor ocurrencia de arenales (Cuadro $\left.\mathrm{N}^{\circ} 1\right)$. El cruce de los arenales con la orientación de los taludes indica la predominancia de los arenales en taludes orientadas al sudeste $(42 \%)$, seguidas de la orientación sudoeste (29\%).

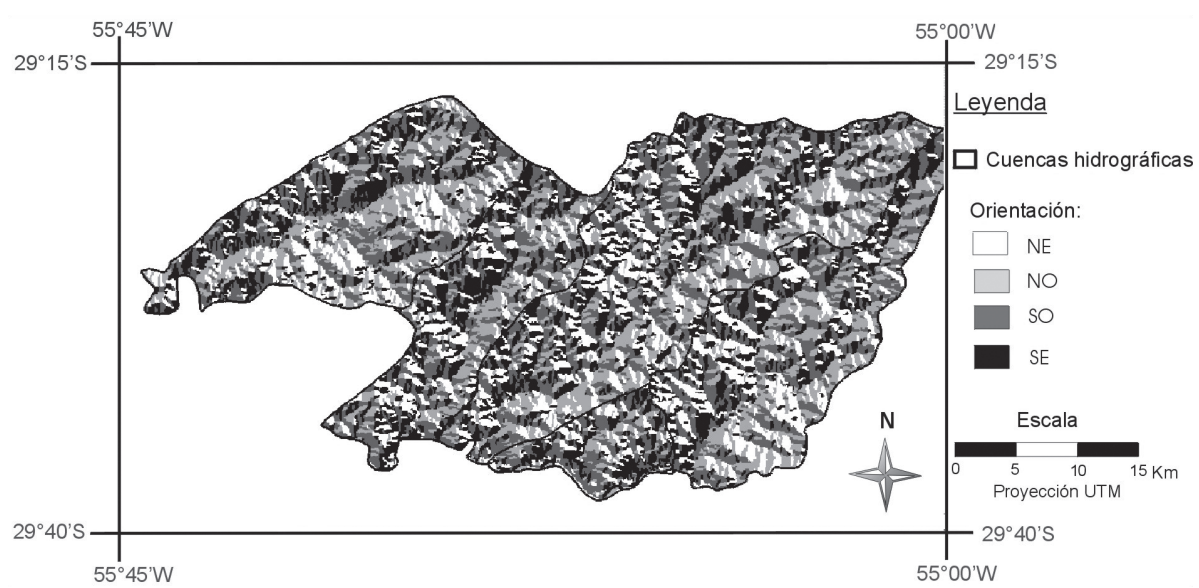

Fuente: Adaptación de Andrades Filho et al. (2007). 
Cuadro $\mathrm{N}^{\circ} 1$

CRUCE ENTRE ARENALES Y ORIENTACIÓN DE LOS TALUDES

\begin{tabular}{|l|c|c|c|c|c|c|}
\hline \multicolumn{1}{|c|}{$\begin{array}{c}\text { Subcuenca } \\
\text { Hidrográfica }\end{array}$} & $\begin{array}{c}\text { Área de las } \\
\text { Subcuencas } \\
\text { (ha) }\end{array}$ & $\begin{array}{c}\text { Área ocupada } \\
\text { por arenales } \\
\text { (ha) } 1989\end{array}$ & \multicolumn{4}{|c|}{$\begin{array}{c}\text { Proporción de arenales con relación } \\
\text { a la orientación de los taludes (1989) }\end{array}$} \\
\hline Ar. Piraju & $36.968,87$ & 406,44 & 3,99 & 10,86 & 29,05 & 56,10 \\
Ar. Inhacundá & $36.729,55$ & 133,92 & 19,39 & 36,36 & 26,06 & 18,18 \\
Sanga Araçá & $9.159,21$ & 25,20 & 11,54 & 3,85 & 50,00 & 34,62 \\
Ar. Miracatu & $59.326,39$ & 557,63 & 20,21 & 17,63 & 32,83 & 29,33 \\
Ar. Caraguataí & $25.622,18$ & 165,63 & 1,08 & 14,59 & 12,97 & 71,35 \\
TOTAL & $843.790,80$ & 1821,25 & 12,00 & 17,00 & 29,00 & 42,00 \\
\hline
\end{tabular}

Fuente: Adaptación de Andrades Filho et al. (2006).

Productos de la modificación del DEM: La red del drenaje y los lineamientos

Uno de los procesamientos realizados en la imagen SRTM fue la modificación del Modelo Digital de Elevación - MDE SRTM. A partir de la imagen SRTM en la resolución de $90 \mathrm{~m}$ - imagen bruta (Figura No 10-A), fue aplicado un método de interpolación sobre imagen para obtener una resolución de 20 metros - imagen interpolada (Figura $N^{\circ}$ 10-B).

A partir del proceso de krigage se observó una significativa la mejoría en la definición de la orientación del relieve, haciendo posible observar la variación de cambios estructurales.

Estudios de Suertegaray (1987, 1998, 2001) dan cuenta que los arenales tienen localización predominante en las cabeceras de las cuencas de drenaje. Para analizar esta relación se realizó un levantamiento cartográfico de detalle de la red de drenaje de las cuencas en estudio, y también se generaron diferentes productos de imágenes sombreadas, a fin de destacar los cursos de agua.

Las tres imágenes en niveles de ceniza usadas en la digitalización del drenaje se presentan en la Figura $N^{0} 11$, según los dis-
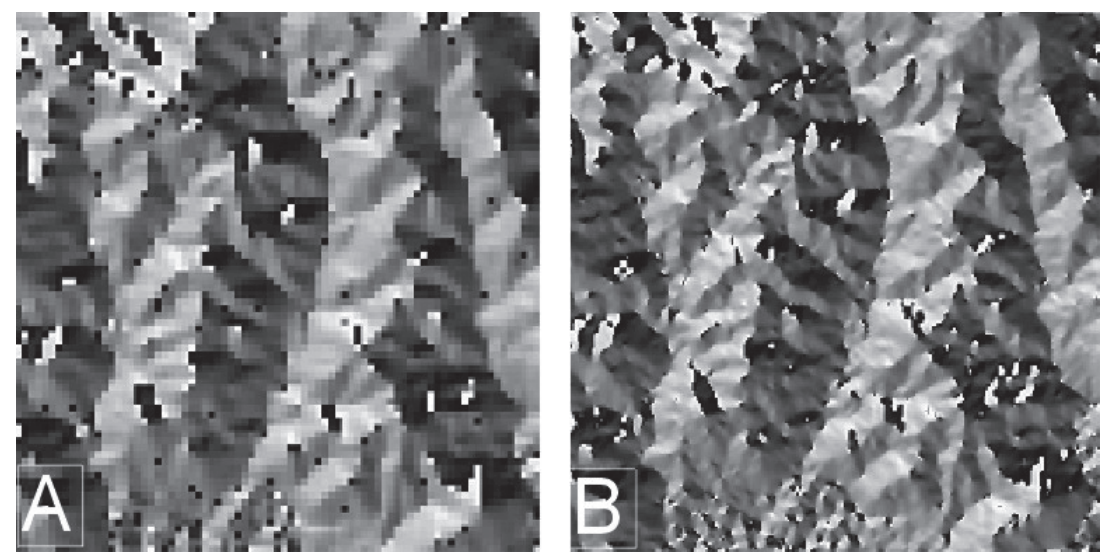

Fuente: Elaboración propia. 
tintos parámetros de iluminación. La imagen 1 presenta las orillas del relieve y áreas de acentuada pendiente con tonos oscuros; las áreas donde el terreno es más plano los tonos de ceniza están más claros. La mayor contribución de esa imagen corresponde a la presentación nítida de las áreas de valles y de rupturas del relieve.

Figura $N^{0} 11$

IMÁGENES SOMBREADAS CON DISTINTOS PARÁMETROS DE ILUMINACIÓN PRODUCTOS SRTM

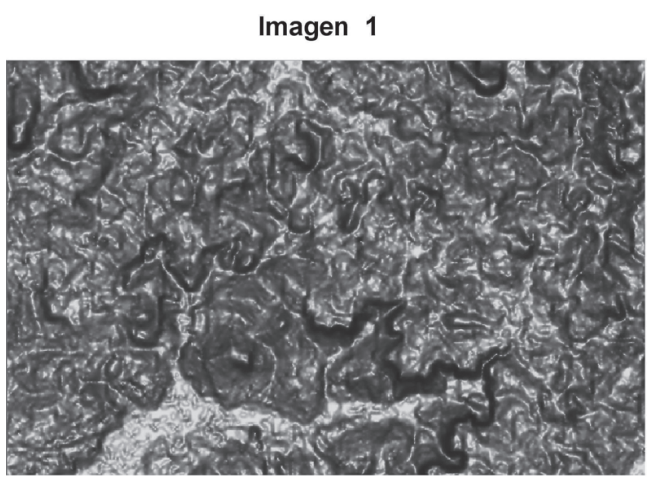

Imagen 2

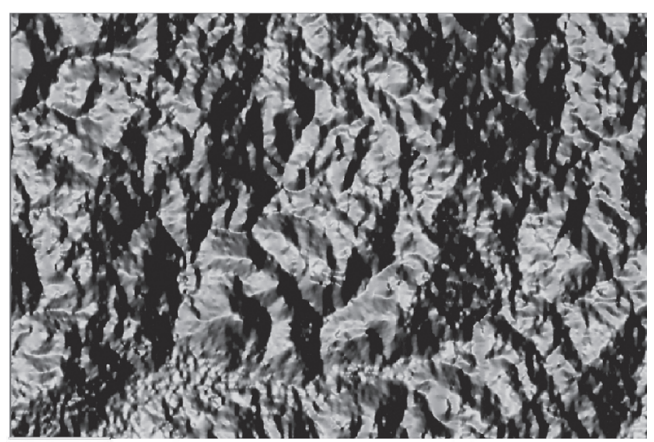

Imagen 3

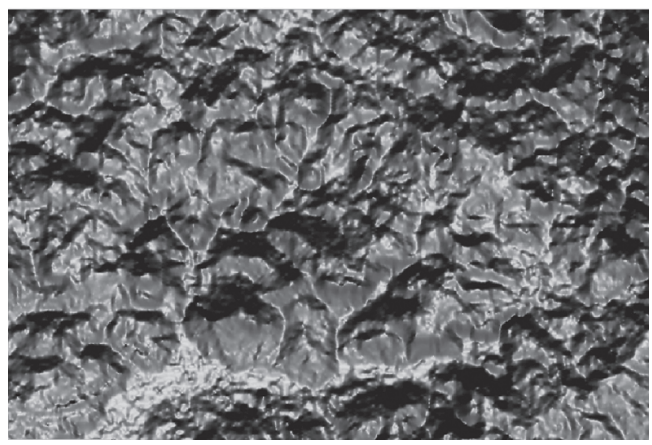

Fuente: Adaptación de Andrades Filho et al. (2007).
En la imagen 2 las áreas donde los niveles del tono ceniza se presentan más claros, son las facetas orientadas al norte. Los tonos más oscuros representan aquellas de orientación el sur. La inclinación del ángulo de la fuente luminosa proporcionó una expresión significativa de la orientación del relieve, dando una idea de visualización en tercera dimensión, donde la topografía del terreno es marcada con gran contraste.

La imagen 3, por su parte, fue procesada con una sutil inclinación del ángulo de la fuente luminosa, que junto a la dirección sur de esta fuente, destacó las líneas de encaje de los cursos de agua. Esta imagen presenta un contraste gradual, donde los cursos de agua están representados por tonos de ceniza más claros, presentando una falsa impresión de corresponder a interfluvios, debido a la dirección sur de la fuente de luminosidad. Las áreas representadas con tonos más oscuros son los taludes orientadas al norte.

Los diferentes tonos de sombreado y contraste de las imágenes proporcionaron una detallada digitalización de los drenajes. A continuación se presentan las líneas de drenaje de un sector del Arroyo Piraju sobre las diferentes imágenes producidas (Figura No 12 ).

Para la definición de los lineamientos estructurales se usó como parámetro, la fuente luminosa con Azimut: $270^{\circ}$, elevación de $45^{\circ}$, con una exageración vertical con valor 70. La digitalización sobre esta imagen presentó resultados significativos, sobre todo en lo relativo a la visualización de calidad de las unidades en estudio. Se evidencian las escarpas pronunciadas, las discontinuidades y otros rasgos definidos como lineamientos estructurales.

Fueron definidos dos conjuntos de lineamientos: Ios principales, que presentaron gran extensión $(>30 \mathrm{Km}$ ) y los lineamientos secundarios, de menor extensión $(<30 \mathrm{Km})$. Los primeros están representados en líneas continuas y los segundos en líneas segmentadas (Figura $N^{\circ} 13$ ).

Como resultado de la superposición de los lineamientos y las redes de drenaje, se 


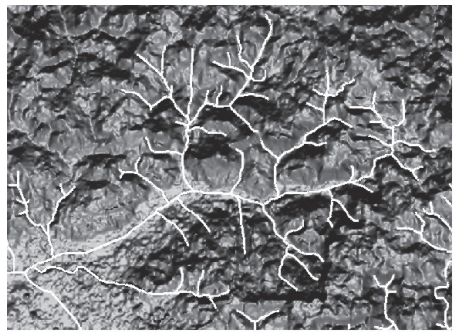

Fuente: Elaboración propia.

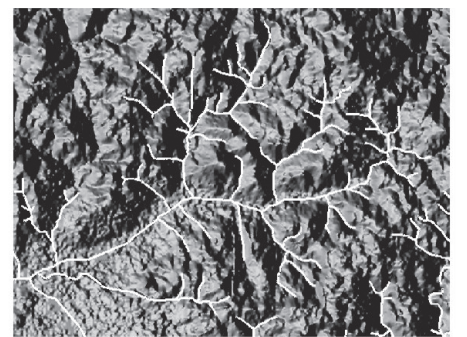

Drenaje

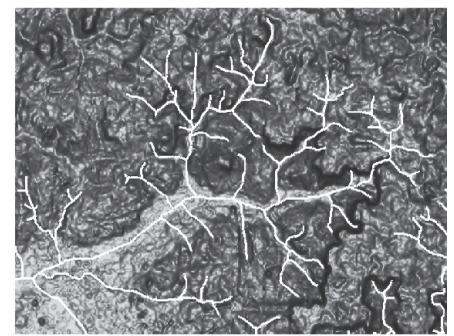

constata que los lineamientos principales (aquellos que definen la macroestructura del relieve) presentan una orientación NE-SW. Estos lineamientos controlan gran parte de los ríos principales que drenan la región. Los lineamientos secundarios (NW-SE) controlan en gran parte el drenaje secundario.

A través de la superposición de los planos de información (Figura $N^{0} 14$ ), de lineamientos estructurales, de los arenales y del drenaje, se evidencia la correlación de estas variables. El cruce de información de los arenales con la orientación de las vertientes indicó el predominio de los arenales en vertientes orientadas al sudeste, seguidas de la orientación sudoeste. Esta orientación se asocia en escala regional ala dirección pre- ferencial de los ríos, esculpiendo consecuentemente vertientes con orientación SE y NW. Considerando la dirección dominante de los ríos secundarios (NW-SE), puede esclarecerse que estos están asociados a los lineamientos de menor extensión, cuya orientación corresponde en gran parte al NW-SE.

A partir de las relaciones entre las variables, se observa que los arenales están ligados principalmente con los drenajes secundarios $y$, por lo tanto, asociados de forma indirecta a los lineamientos de menor extensión, lo que confirma la predominancia de orientación SE-SW. Además, en el mapa de superposición de los arenales con los lineamientos es posible observar una regularidad, un patrón, entre ambos.

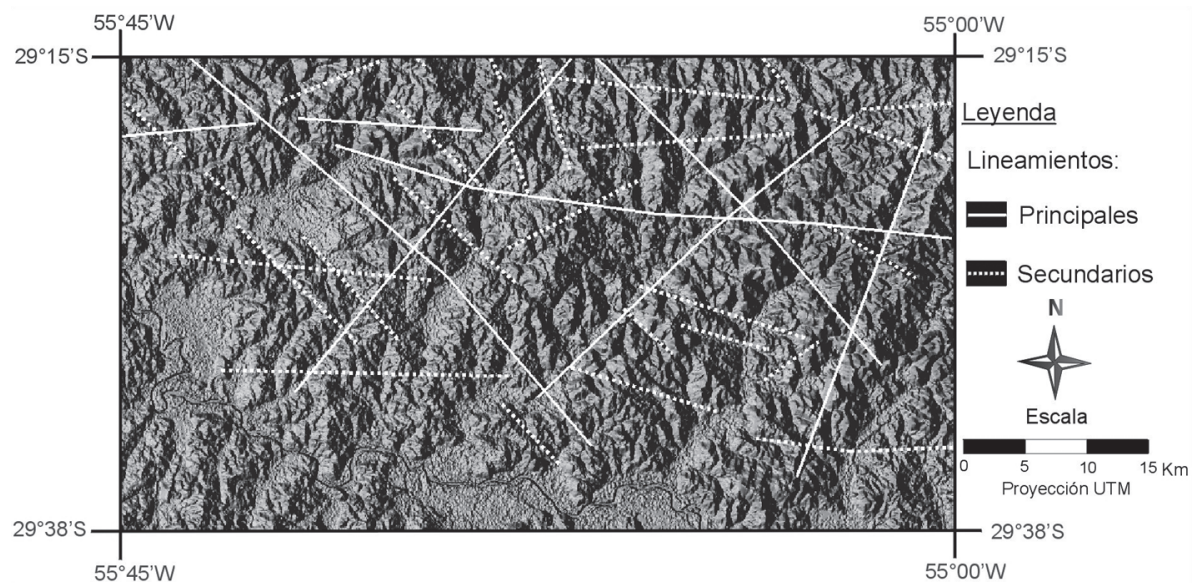

Fuente: Elaboración propia. 
Figura $\mathrm{N}^{0} 14$

SUPERPOSICIÓN DEL DRENAJE, LINEAMIENTOS Y ARENALES, EN EL ÁREA DE ESTUDIO

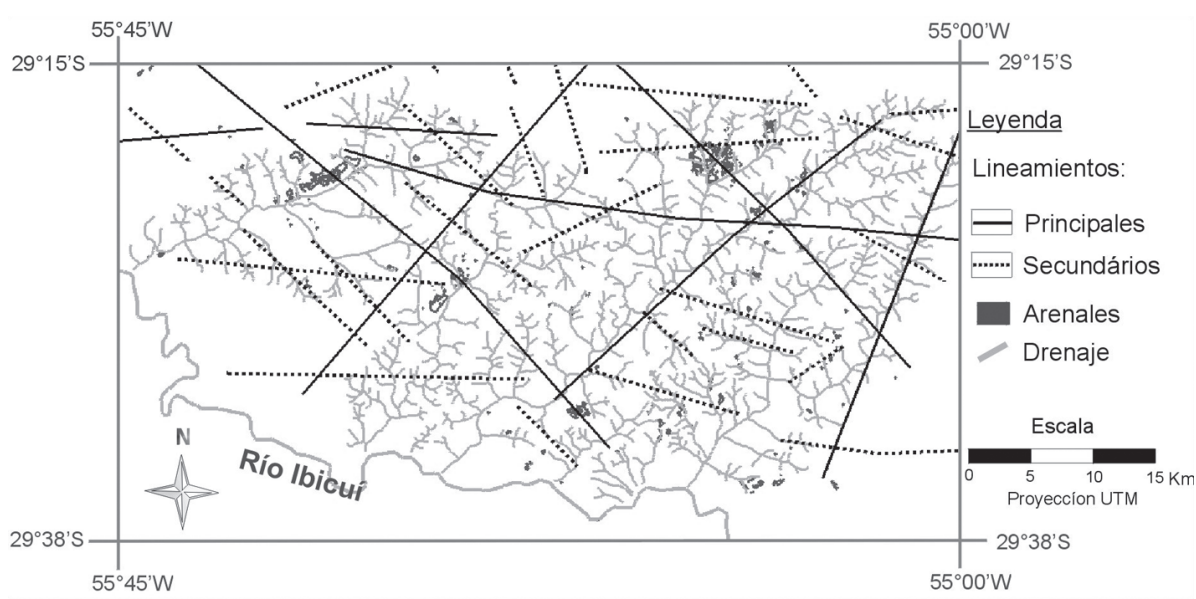

Fuente: Adaptación de Andrades Filho et al. (2007).

Para un mayor detalle de la relación establecida, Andrades Filho (2007) calculó el RDE (Relación de Pendiente/ Extensión) a través de segmentos fluviales. Este índice fue empleado toda vez fue posible realizar una evaluación de detalle de la tectónica, y como las manchas arenosas poseen cierta dispersión en las cuencas hidrográficas estudiadas, fue necesario realizar la evaluación local.

La detección de posibles deformaciones neotectónicas fue analizada a través de algunos parámetros morfométricos construidos por Etchebehere et al. (2004), con base en Hack (1973). La ocurrencia de arenales se presenta de manera general, relacionada con las posibles áreas de deformaciones neotectónicas.

Compartiendo lo expresado por Trainini (2005), existe la posibilidad de que solevantamientos por falla, que la exposición de la arenisca y la consecuente búsqueda del nivel de base de la erosión, preexistente, desencadenen procesos de arenización.

En consecuencia, se podría señalar que los lineamientos estructurales están contribuyendo a la formación de arenales, en la medida que estos tienen su origen asociada a la formación de escalones de abatimiento y a flujos concentrados en canales, surcos o regueros (Uagoda, 2004). Estos surcos y cárcavas en general se desencadenan en las cabeceras fluviales y en ríos de primer orden. Los trabajos de campo realizados permiten concluir que durante un determinado período estuvieron recubiertos por un manto arenoso no consolidado, que luego presentó procesos de reactivación. Tales procesos, al profundizar los canales fluviales, transportan esos materiales para los exutorios, contribuyendo así con ese aporte de masa a la formación de los arenales.

\section{Consideraciones finales}

El uso de la imagen SRTM fue fundamental en la generación de los datos obtenidos en este trabajo. El tratamiento de la imagen y la generación de subproductos fue de absoluta importancia, pues proporcionó un avance en la investigación sobre los procesos de arenización, levantando hipótesis sobre la génesis de la ocurrencia de los arenales en el sudoeste del Rio Grande do Sul, bajo la consideración de los lineamientos estructurales.

El análisis de la relación entre los lineamientos estructurales con la disposición del drenaje, la orientación de las vertientes y la ocurrencia de arenales, demostró que existe la posibilidad de que estas variables estén 
fuertemente asociadas con la estructura del basamento del área de estudio.

La formación de los arenales, en general asociada a cabeceras de drenaje, puede estar asociada a lineamientos estructurales de la región. Entretanto, es necesario una profundización de las investigaciones con vistas a identificar posibles lineamientos de menor tamaño, así que posibiliten análisis de mayor detalle de la disposición de estos y la distribución espacial de manchas arenosas.

\section{Referencias bibliográficas}

ANDRADES FILHO, C.; SUERTEGARAY, D. e GUASSELLI, L. Arenização no Sudoeste do RS: investigação sobre a relação entre areais, drenagem e orientação de relevo. IAG/UGB. VI Simpósio Nacional de Geomorfologia e Regional Conference on Geomorphologie, 2006, Goiânia. Anais/ Actes - VI Simpósio Nacional de Geomorfologia e Regional Conference on Geomorphologie. Goiânia: IAG/UGB, 2006, Vol. 2.

ANDRADES FILHO, C.; GUASSELLI, L. A. e SUERTEGARAY, D. M. A. Investigação sobre a relação entre lineamentos estruturais e a ocorrência de areais no sudoeste do Rio Grande do Sul. XII Simpósio Brasileiro de Geografia Física Aplicada, 2007, Natal - RN. Anais do XII Simpósio Brasileiro de Geografia Física Aplicada. Natal: UFRN, 2007, Vol. XII, p. 243-257.

ANDRADES FILHO, C. O. Arenização e tectônica: Contribuição estrutural ao estudo da gênese dos areais no sudoeste do Rio Grande do Sul. Trabalho de Conclusão do Curso de Geografia. Porto Alegre: Departamento de Geografia, Instituto de Geociências, Universidade Federal do Rio Grande do Sul, 2007.

CMARA, G.; SOUZA, R.C.M.; FREITAS, U. M. and GARRIDO, J. SPRING: Integrating remote sensing and GIS by object-oriented data modelling. Computers \& Graphics, 1996, No 20, p. 395-403.

ETCHEBEHERE, M. L. C.; SAAD, A. R.; PERINOTTO, J. A. J. e FULFARO, V. J. Aplicação do Índice "Relação Declividade-Extensão - RDE" na Bacia do Rio do Peixe (SP) para detecção de deformações neotectônicas. Revista do Instituto de Geociências USP - Série Científica, 2004, Vol. 4, N², p. 43-56.

FARR, T. G. et al. The Shuttle Radar Topography Mission. Revista Geophys, 2007, No 45 .

FRASCA, A. A. S. Aplicações de Sensoriamento Remoto e análise de lineamentos em estudos tectônicos na região de São Francisco de Assis, Porção da Borda Meridional da Bacia do Paraná, RS. Dissertação de Mestrado em Sensoriamento Remoto. Porto Alegre: Centro Estadual de Pesquisas em Sensoriamento Remoto e Meteorologia, 1996.

HACK, J, T. Stream-profile analysis and stream-gradient index. Journal Research of the U. S. Geol. Survey, 1973, Vol. 1, No 4, p. 421-429.

MINISTÉRIO DO MEIO AMBIENTE Plano Nacional de Combate à Desertificação. Brasília: Centro de Sensoriamento remoto, IBAMA, 1997.

NATIONAL AERONAUTICS AND SPACE ADMINISTRATION (NASA). Portal Web. USA: NASA, 2003. Disponível en Internet: ftp://e0srp01 u.ecs.nasa.gov/srtm/version2.

SUERTEGARAY, D. M. A. A Trajetória da Natureza: um estudo geomorfológico sobre os areais de Quarai - RS. Faculdade de Filosofia, Letras e Ciências Humanas, instituição de defesa de tese. São Paulo: USP, 1987.

SUERTEGARAY, D. M. A. Deserto Grande do Sul: Controvérsias. 2. Ed. Porto Alegre/ RS: Universidade Federal do Rio Grande do Sul, 1998.

SUERTEGARAY, D.; GUASSELLI, L. e VERDUM, R. (Org.) Atlas da Arenização: sudoeste do Rio Grande do Sul. Porto Alegre: Secretaria da Coordenação e Planejamento do Governo do estado do Rio Grande do Sul, 2001.

TRAININI, D. R. A influência da neotectônica no assoreamento de bacias. ABRH. Simpósio Brasileiro de Recursos Hídricos. João Pessoa: ABRH, 2005. 
UAGODA, R. Degraus de abatimento: estudo comparativo em cabeceiras de drenagem: bacia hidrográfica do Arroio Puitã e bacia hidrográfica das nascentes do Rio das Antas/RS. Trabalho de Conclusão do Curso de Geografia. Porto Alegre: Universidade Federal do Rio Grande do Sul, Instituto de Geociências, Departamento de Geografia, 2004.
VALERIANO, M. Modelo digital de elevação com dados SRTM disponíveis para a América do Sul. São José dos Campos: Instituto Nacional de Pesquisas Espaciais, 2004. 